\title{
Aproximaciones al estudio de la pasión en la obra de Jorge Luis Borges. Duda y desesperanza en El Muerto
}

\author{
Approaches at the study of passion in Jorge Luis \\ Borges' work. Doubt and hopelessness in El Muerto
}

Luis Alejandro Nitrihual Valdebenito ${ }^{1}$

\section{Resumen}

El presente trabajo investiga dos pasiones -duda y desesperanza- en el cuento El Muerto, perteneciente al libro El Aleph, de Jorge Luis Borges. Partiendo de las propuestas de Paolo Fabbri y Aljirdes Greimas, queremos mostrar cómo las pasiones se encuentran patentes en esta obra borgeana particular. Para ello, nos hemos servido de la metodología de Greimas sobre estructuras actanciales y modales, que son un elemento primordial para determinar cómo se manifiesta una pasión en el plano textual.

\section{Palabras clave}

Borges, pasión, duda, desesperanza.

\section{Abstract}

The following work investigates two passions - doubt and hopelessness- in the tale El Muerto, which belongs to the book El Aleph by Jorge Luis Borges. Our theoretical framework is Paolo Fabbri's and Aljirdes Greimas' works about passion and narrativity theory. In order to do this, we have used Greimas' methodology on actantial model, which is a fundamental component to determine how a passion is declared in the textual level.

\section{Keywords}

Borges, passion, doubt, hopelessness.

Artículo recibido el 10 de julio de 2010 y aprobado el 28 de marzo de 2011

1 Profesor Universidad de la Frontera. Departamento de Lenguas, Literatura y Comunicación. Magister en Ciencias de la Comunicación, Temuco, Chile. anitrihual@ufro.cl 


\section{Hipótesis centrales, metodología y objetivos de la investigación}

La obra de Jorge Luis Borges ha sido investigada fuertemente a partir de la década del 70 y hasta la actualidad (Alazraki, 1974; McMurray, 1982; Sarlo, 1995; Toro, 1999; Kazmierczak, 2001; Savater, 2008, entre tantos otros) ${ }^{2}$. Su vida ha sido biografiada otras cuantas veces (Monegal, 1987; Bloom, 1986; Ferrari, 1985; Teilteimboim, 1995). Esto, evidentemente, habla de la relevancia que ha cobrado su obra como una de las más importantes de habla hispana en el siglo XX. Sin embargo, también acarrea dos consecuencias: 1) positivamente, nos entrega una gran cantidad de material que ayuda a nuevos estudios como el nuestro, pero 2) disminuye las posibilidades de investigación, pues debe cuidarse de no caer en la redundancia.

Atendiendo a la primera consecuencia, hemos detectado que las investigaciones sobre la obra borgeana han puesto especial interés en su expresión y contenido como manifestación de un discurso altamente racional. Esta racionalidad se ha planteado principalmente, debido a las temáticas filosóficas que motivan al autor y que hacen de su obra el lugar ideal para investigaciones tanto literarias como filosóficas.

La presente investigación, como hipótesis central, si bien concuerda con el complejo y sublime paisaje que es la obra de Borges, muestra cómo la racionalidad se encuentra inevitablemente unida a la pasión en la obra borgeana; tema hasta ahora poco tratado, pero que cobra relevancia en la semiótica. De este modo, pretendemos hacernos cargo y solucionar la segunda consecuencia, referida a la originalidad que debe tener una propuesta investigativa.

Para ello hemos precisado de las investigaciones del italiano Paolo Fabbri (1995, 2000), quien, retomando las investigaciones planteadas por Fontanille y Greimas (1994), intenta superar en semiótica la dicotomía tradicional entre razón y pasión, propo-

2 Para un mayor detalle de la amplia bibliografía sobre la obra borgeana, consultar el texto que Jesús Benítez Villalba compendia sólo desde 1973-1983. Disponible on line en http://revistas.ucm.es/ fll/02104547/articulos/ALHI8585110190B.PDF. Consultado en octubre de 2008. niendo el estudio de las pasiones en los discursos. El campo abierto por Fabbri, y él que retomamos nosotros como metodología de análisis, se complementa necesariamente con las metodologías planteadas por A. J. Greimas (1983, 1989), Greimas y Courtés (1982) y Greimas y Fontanille (1994), y El grupo de Entrevernes (1989). Esto es, nuestra metodología de análisis es el análisis actancial y narrativo del cuento El Muerto, aparecido en la colección de cuentos El Aleph de Jorge Luis Borges (1984).

Nuestros objetivos, en esta medida, son los siguientes:

1. De manera general, contribuir a la explicitación conceptual de lo qué son las pasiones y lo que representan en la superación, en semiótica, del dualismo razón/pasión.

2. De manera general, mostrar cómo es posible comenzar un estudio de las distintas pasiones que se manifiestan en la obra de Jorge Luis Borges.

3. De manera puntual, demostrar cómo dos pasiones particulares, la duda y la desesperanza, se manifiestan textualmente en un cuento del autor argentino.

En este ejercicio, indagaremos en dos pasiones puntuales: la duda y la desesperanza. Veremos cómo ambas se encuentran fuertemente vinculadas y modalizadas, esto mediante la explicación de los principales programas narrativos y los actantes, en el juego de acciones que encadenan y desembocan en pasiones determinadas.

\section{El giro de la semiótica para una investigación de la pasión}

Tal como hemos planteado en un trabajo anterior (Nitrihual, 2008b), la semiótica ha devenido actualmente en semióticas particulares y en una semiótica que se abre hacia objetos de investigación no tratados tradicionalmente por la ciencia, como son los sentimientos y las pasiones, pero que han cobrado relevancia sobre todo desde la filosofía y sicología (Marina, 2007) y también desde la semiótica, desde principios de los años noventa (Greimas y Fontani- 
lle, 1994; Paolo Fabbri, 1995, 2000). Esto es algo que se hacía necesario en un estado del arte donde las disciplinas convergen y exigen interdisciplinariedad (Blanco, 2006, p. 2).

Umberto Eco (1999) propone de manera tajante, al final del Tratado de Semiótica General, que el verdadero protagonista del libro es el proceso semiótico. En efecto, se observa que en la semiótica de Umberto Eco, que emana, en parte, de los trabajos de Charles Pierce, subsiste una antigua tradición filosófica de dualidad, que tiene su origen en el movimiento cartesiano que separa de manera contundente sujeto y objeto.

En una entrevista realizada por Xavier Ruiz Collante (1997) a Fabbri, éste señala:

Bueno, hay personas como Umberto Eco, por ejemplo, que piensan que la semiótica es una filosofía del lenguaje, es una teoría general que permite cuestionamientos filosóficos sobre qué es el lenguaje, sobre qué es el hecho de hablar, sobre qué es la referencia a la realidad, la relación kantiana entre el hombre que piensa y la realidad.

La postura de Paolo Fabbri busca desmarcarse de las problematizaciones epistémicas que tanto atormentaron o gustaron a Eco. En esta tarea, Fabbri ya no tendrá como eje fundacional la perspectiva del signo y se desplazará hacia una "indagación con vocación científica de los sistemas y los procesos de significación" (Fabbri, 2000, p. 56).

La relación tan estudiada entre realidad y signos, como una dicotomía insalvable, es una cuestión que es parcialmente solucionada con una armonía oriental de no-oposición. En la citada entrevista de Ruiz Collante (1997) Fabbri señala:

La idea, el pensamiento, la realización de un concepto, es realidad. No hay diferencia entre ficciones y descripción fiel de la realidad ... Yo creo que la diferencia entre la vieja idea de que hay un sujeto que piensa idealmente, hay ideas, y afuera está lo real, es absurda.

Estamos ante una postura que también tiene algo de ético. La palabra no es sólo convencionalidad y arbitrariedad, es una relación sentimental que establecemos con el otro. Cuando nos relacionamos comunicativamente estamos estableciendo lazos afectivos que nos comprometen con el interlocutor. Desde ese punto de vista, me atrevo a plantear que Fabbri le proporciona a la semiótica un ánima ética.

\section{La narratividad}

Este es un tema vital en toda la semiótica. La tradición semiológica, de cuño eminentemente lingüístico, ha establecido que el estudio de la narratividad es el equivalente al estudio de los relatos.

En este sentido, tenemos que los relatos, sean orales o escritos, constituyen un conjunto organizado de partes que, con fines de metodológicos, se van descomponiendo para su estudio. Sin embargo, colocados en la posición de Fabbri, tendremos que la narratividad se plantea como concatenación ya no sólo de estructuras lingüísticas formales, sino de acciones y pasiones, que conducen a la semiótica -desde los objetos o cosas- a los sujetos, verdaderos protagonistas de todo proceso semiótico. Este, no hay duda, fue el norte de Greimas y Fontanille (1994) cuando subtitulan su libro como De los estados de cosas a los estados de ánimo.

\section{La pasionalidad}

Barthes, señala Fabbri, es el primero en intentar incluir en la semiótica el componente afectivo. Lo negativo es que se queda en el intento y no logra capitalizar la propuesta. Realiza únicamente el reconocimiento de una problemática.

Es interesante, en este punto de la discusión, la pregunta: ¿por qué la pasión y no el afecto?

Fabbri entrega la respuesta al volver a desmarcarse de la dicotomía clásica entre razón- pasión. Se trata de devolverle a la pasión su significado original que la vincula a la acción como caras de una misma moneda. Por lo mismo, podría decirse que la semiótica de la pasión es una semiótica de la acción. En nuestras relaciones tenemos una recursividad de acciones pasionales que nos comprometen.

Si ya no estamos sólo en el plano de la idealización conceptual, sino en el de la "recursividad pasional", tendremos que la semiótica se ocupará de estudiar actos dadores de sentido; estos se generan no 
sólo por las palabras, también con piezas musicales, gestos, etc.

La semiótica es una disciplina, siguiendo el razonamiento anterior, necesariamente multimedial. Piensa que todo lenguaje tiene su particular componente expresivo que lo vincula a un contenido. Los signos son, en este caso, elementos activos y performativos al comprometer acciones.

\section{Tipología y configuraciones pasionales}

La semiótica de las pasiones busca descomponer los relatos en fenómenos específicos pasionales, como por ejemplo la avaricia, los celos, la ira, la felicidad, etc., para luego describirlas en función de sus estructuras internas - procesos a los que dan lugar- $y$ las transformaciones narrativas que producen (Fabbri, 2000).

Los cuatro componentes pasionales que entrega Fabbri $(1995,2000)$ están presentes en los procesos de significación más allá de la substancia que las compongan (relatos escritos, orales, piezas musicales, gestos, etc.).

- Componente modal: se refiere a las modalidades clásicas - poder, saber, querer, deber- y también a las modalidades - posible/imposible, cierto/incierto-.

Ejemplo: la curiosidad es una pasión del saber. La venganza una pasión del deber.

- Componente temporal: en las pasiones interviene, evidentemente, el tiempo. La esperanza, citada por Fabbri, tiene un importante componente temporal.

- Componente aspectual: relacionado con la temporalidad, tiene que ver con la vivencia de la pasión por parte de un observador externo -duración, incoación, terminación, principio-.

Ejemplo: miedo y terror son dos palabras que describen una situación particular, pero en duración tienen distinciones radicales. Mientras la primera es durativa, la segunda, el terror, es puntual e intensa.

- Componente estésico: en toda pasión está involucrado el cuerpo. La pasión origina cambios en el cuerpo (Fabbri, 2000) y es un aspecto relevante en el análisis semiótico.

\section{La duda como pasión}

El lenguaje es emoción y pasionalidad. No es tampoco, como el mismo Fabbri indica, que las pasiones no se hayan estudiado antes. Por ejemplo, Charles Sanders Pierce en su teoría de las inferencias lógicas, desarrolla la idea de la duda como parte fundamental y gravitante del conocimiento, y Descartes, el filósofo racional, produce un Tratado de las Pasiones. En palabras de Fabbri, nadie relaciona un signo con otro inferencialmente sin antes tener dudas; y la duda es una pasión relacionada con el conocimiento:

Aún así, hasta que podamos lograr dudar de una proposición no puede tener lugar ninguna investigación real acerca de su verdad" (Pierce 1902, p. 32).

Nos interesa por ahora despejar lo que entenderemos por duda y desesperanza, para luego poder aplicarlo al análisis del cuento El Muerto, que aparece en El Aleph, libro vital en la obra de Borges por la madurez que logra el escritor.

\section{La duda: expansión de los límites de Fabbri}

Intentamos ir más allá de lo propuesto por Fabbri (2000) cuando señala que la duda es una pasión del conocimiento y por tanto modalmente de un querersaber, pues consideramos que la duda es vital en todas las decisiones del hombre. Esto busca abrirnos paso para el análisis narrativo posterior.

Una primera aproximación desde el diccionario ${ }^{3}$ nos otorga las primeras luces sobre el concepto de duda. Tenemos que se trata de:

- Incertidumbre, suspensión del juicio, sea definitiva (escéptica) o provisional (metódica, cartesiana).

Suspensión del juicio, pues la duda es un estado en que el sujeto, puesto sobre dos o más opciones, se

3 De: Diccionario Enciclopédico 1995. Grijalbo. Barcelona. 
encuentra en situación de no decisión, lo que produce un estado de tensión interna.

Etimológicamente, la palabra proviene del latín dubitare y se encuentra vinculada, primariamente, a vacilación, irresolución, perplejidad. Al descomponerla lexicográficamente, nos encontramos con:

/vacilación/, /irresolución/, /perplejidad/.

Se puede establecer que si la duda comporta originariamente el sema /perplejidad/e /irresolución/, se trata de un estado pasional de máxima tensión. La duda, podemos señalar en una primera conclusión, precisa de un estado pasional que le preceda: la decisión. De este modo, el recorrido que tendría es:

\section{duda}

decisión $\rightarrow$ /perplejidad/+/irresolución/.

Digamos que un sujeto que se encuentra en un estado de duda, debió transitar necesariamente por otro de decisión, pues la duda es un estado transitorio altamente modalizado y que se basa en un no-poder-hacer y no-poder-ser, que se traduce en impotencia e imposibilidad respectivamente, y como veremos en el caso del personaje Otálora del cuento El Muerto -y también en Emma Zuns-, puede transformarse en una imposibilidad constitutiva. Siguiendo la tradición, veamos los dos cuadros semióticos que registran las categorías del ser y el hacer:

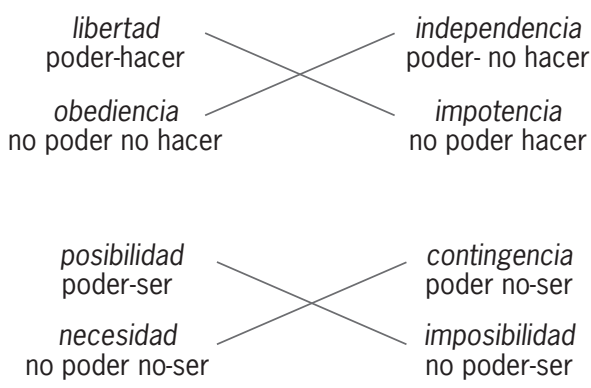

La duda, cuando es transitoria, se mueve hacia un estado de conjunción del sujeto con su objeto, que se transforma en la opción elegida. De este modo, evidentemente se trata de una pasión que tiene un carácter volitivo y de no-acción, en que provisional- mente el sujeto es incapaz de tomar una decisión, lo que produce /incertidumbre/.

Por su parte, la decisión, o el estado precedente a la duda, vista desde el diccionario es:

- Opción que se toma o da ante un problema.

- Seguridad de sí mismo.

La última definición es más introspectiva al establecer un estado eminentemente cognitivo. La decisión contiene un sema de /tranquilidad/y también se encuentra altamente modalizada por un poder-hacer y poder-ser, que garantiza la libertad del sujeto para tomar una opción y la posibilidad de conjuntarse con su objeto.

\section{Desesperanza}

El tema de la duda es vital en la obra borgiana y nos lleva inevitablemente a otro estado pasional, la desesperanza. Siguiendo el procedimiento anterior, nos aproximaremos desde el diccionario. Éste señala que se trata de:

- Falta de fe en la consecución de lo que se espera o desea.

- Pérdida de la esperanza.

La segunda definición evidencia que se trata de un estado que no puede esclarecerse sin su opuesto: la esperanza. De hecho, se descompone etimológicamente en des y esperanza. Proviene del Latín despero, que destaca este estado de carencia.

Esperanza por su parte es definida como ${ }^{4}$ :

- Confianza en lograr una cosa o en que se realice lo que se desea.

- Alimentarse o vivir uno de esperanzas, esperando sin fundamentos conseguir lo que se desea.

Se cruzan notoriamente las definiciones primeras, que se refieren a un estado de carencia, y por eso indicamos que la desesperanza es ininteligible sin su opuesto. Por su parte, la segunda definición de esperanza destaca el papel físico que entrega esta

4 Definiciones tomadas de Gran Enciclopedia Larousse. 1992. Tomo 7 y 8 . Planeta. Barcelona 
pasión. Nos alimentamos, hecho que ocurre sólo en la vida, de esperanzas, pues nos permiten un estado de calma que no encontramos presente en la desesperanza.

De este modo, si la esperanza es un estado vital, la desesperanza, al contrario, tiende hacia la muerte.

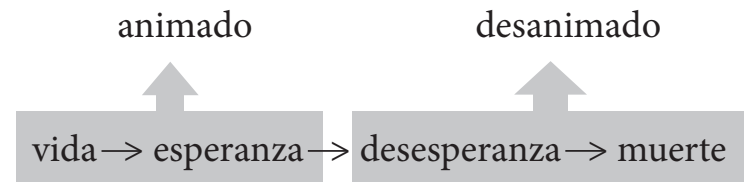

La desesperanza es una pasión cognitiva que produce una somatización del sujeto, que expuesto a este estado, carece por completo de seguridad.

Ahora, si tomamos el lexema esperanza obtendremos que se compone, entre otros, del sema /seguridad/. Por el contrario, la desesperanza es /incertidumbre/. Recordemos que ya antes, cuando examinamos la duda, encontramos estos semas, que podrían considerarse Núcleos Sémicos de ambas pasiones, que se cruzan de manera evidente. Nos hallamos ante un estado pasional que ha pasado de la tensión, de la duda, al decaimiento.

Podemos aventurar lo siguiente:

1. La desesperanza es un estado de carencia. Una situación de disyunción del sujeto.

2. Estamos ante estados pasionales que tienden hacia sus opuestos y se manifiestan en correlación con ellos. El estado de desesperanza ha aparecido por la /perplejidad/, /irresolución/ que ha llevado a la pérdida de algo que antes se tuvo: esperanza.

\section{La obra se llama El Muerto. Clarificación metodológica}

Siguiendo las propuestas de Paolo Fabbri (1995, 2000), nos hemos abocado a un trabajo que va más allá del análisis de personajes y situaciones particulares dentro del texto. Se trata de entender al discurso como constructor de sentido. Pensar de este modo, es acercarse a A. J. Greimas (1983, 1989); en él hemos sustentado nuestra metodología de análisis.

Creemos que realizar el análisis en un cuento de Borges, es un trabajo interesante pues da cuenta del texto como proceso vivo y se una fuerza pasional interesante. Es además funcional al objetivo particular de la investigación, que es mostrar la presencia de dos pasiones particulares, duda y desesperanza, que se encuentran vinculadas en sus Recorridos Narrativos (RN).

\section{Organización Narrativa ${ }^{5}$}

Todo texto tiene una organización que asegura su coherencia. La coherencia es vital, pues permite la clausura del espacio textual y la comunicación efectiva con el destinatario. El concepto de coherencia también ha sido trabajado por Lozano, Peña-Marín y Abril (1999), donde se recalca su importancia.

Ahora bien, en la historia relatada encontramos dos personajes que son el motor de la fábula, Otálora y Bandeira. Antes de pasar al estudio de ambos personajes y sus respectivos Programas Narrativos, hagamos un breve resumen de la historia que contribuya a contextualizar nuestro trabajo.

Otálora es un muchacho que, luego de matar a un hombre, debe huir de su país natal, Argentina, a Uruguay. Para que su huida tenga un buen fin, el "caudillo de la parroquia" le da una carta dirigida a Azevedo Bandeira, un hombre que tiene muchos negocios de contrabando y que puede ayudarle. Con esa carta como ayuda, parte de su tierra Otálora. Una vez en Uruguay no logra ubicar a Bandeira. Desanimado, recorre las calles desconocidas y en un altercado, donde va a dar por casualidad, se entera de que uno de los que pelea es el mismo Bandeira. Decide, en ese momento, no presentar la carta de recomendación, y ganarse todo por sus propios medios. Se entromete en la pelea para que lo conozcan. Agradecido, Bandeira le ofrece compartir con ellos una fiesta. Al parecer, tienen por costumbre pelear pues el adversario de Bandeira comparte la mesa, igual que todos.

Invitado por el propio Bandeira, Otálora empieza a trabajar para él. Luego de un tiempo se da cuenta de que los negocios del jefe son cuantiosos, es un

5 “La organización narrativa asegura la coherencia de los elementos de un relato en la sucesión. Ella es la que regula el paso de un estado inicial a un estado final por medio de una transformación" (Grupo de Entrevernes, 1989, p. 26). 
hombre de gran poder al que respetan en todos lados. Ser hombre de Bandeira es tener un salvoconducto y obtener respeto inmediato.

Entonces se pregunta (como Satanás) ${ }^{6}:$ ¿por qué debe estar al servicio de Bandeira, cuando podría tener su propio negocio? Comienza, desde ese momento, un plan de eliminación paulatina de Bandeira. No quiere (o puede como veremos) eliminarlo de manera violenta sino irlo desplazando poco a poco.

Efectivamente, al cabo de un tiempo logra desplazar a Bandeira. Ordena y hace negocios como si fuera el jefe. Incluso posee a la mujer de Bandeira, signo de poder, como todo lo que le rodea. El final es súbito: cuando Otálora piensa que su victoria es inminente, deviene su muerte.

Otálora, como ya lo dije, es el actante sobre el que gira el relato, es sujeto y objeto del mismo. El narrador nos indica, en el comienzo, que es una historia sobre el destino mortal de Otálora. Con esto, asegura un recorrido virtual del personaje hacia el fracaso. Se puede establecer, como vemos en el cuadro semiótico, que Otálora, como es narrativizado por el narrador, se encuentra en una situación de virtualización de muerte.

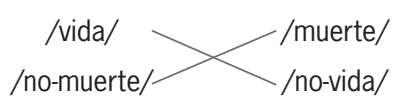

Es un actante que tiende hacia la muerte, se encuentra en una posición precaria de no-muerte. A lo largo del relato, no hace otra cosa que seguir los pasos de su destino. Convengamos que la introducción en el relato del lexema destino, "A quienes lo entienden así, quiero contarles el destino de Benjamín Otálora" (Borges, El Muerto, 1984), es de suma complejidad, comporta entre otros semas el de /duratividad/, /inalterabilidad/ y /encadenamiento/. El lexema destino está dotado, en gran parte, de semas relacionados con el tiempo, uno de cuyos núcleos sémicos es el de /duratividad/. El resultado que vemos es que, si bien desde el principio del relato se conoce en final, ("y que murió en su ley, de un balazo") [Borges, El Muerto, 1984]), lo que nos propone el narrador es reconstruir los pasos de Otálora hasta

6 Resalto la posibilidad intertextual del relato. su muerte. El destino es desconocido en cuanto a los /encadenamientos/ de hechos que condujeron a la muerte. Para ello es necesario entonces indagar en la performance de Otálora.

\section{Hacer de Otálora (S1)}

Otálora es un actante que va operando transformaciones a lo largo de todo el texto. En la primera parte -en el segundo párrafo- es el causante de un estado de disyunción en otro actante que se convierte, más que en un sujeto actante, en un objeto actante.

Esta primera transformación disyuntiva no es para nada menor en el relato. Otálora se manifiesta como un sujeto que transforma y busca transformar con su hacer de manera disyuntiva; se convierte en un operador de carencia. En el primer caso logra quitar vida, luego desea quitar todos los bienes a Bandeira, hecho que finalmente resulta frustrado.

Es necesario mostrar como S1 se encuentra modalizado en el plano factitivo, pensando que las pasiones, que hemos buscado indagar desde una teoría de la narratividad, tienen un radical modal, como lo indica Paolo Fabbri (1995, p. 45). Daremos cuenta de las modalidades que se encuentran en relación con el componente pasional indagado:

a. Por el querer: el sujeto tiene una constante a lo largo del texto: querer-hacer. Su querer-hacer no es producto de un plan elaborado. Cuando mata a un hombre es un hecho fortuito, cuando se encuentra con Bandeira también, y luego, cuando ha planeado algo, esto se trunca. Su querer está rodeado por lo fortuito. El querer-hacer, como lo señala Greimas (1989, p. 45), es una competencia virtualizante que se abre cuando Otálora conoce a Bandeira y desarrolla su performance, con miras a la consecución o conjunción con lo que no le pertenece.

b. Por el poder: Otálora ejerce el poder de manera fortuita. Siempre se mueve hacia el resto de los personajes con disyunción, ya sea quitando la vida o buscando despojar a Bandeira de lo que le pertenece. En cualquier caso, el adyuvante de este poder es su suerte, que hasta el final parece sonreírle. 
Otálora es un actante que se mueve en lo casual. Por eso, el poder que ejerce no es duradero. Se trata más de un querer-tener-poder, que se traduce a la larga en un no-poder-hacer, impotencia que se descubre al final de texto.

\section{La parte de Bandeira}

Veamos el actuar de Bandeira antes de pasar al plano discursivo que propone el Grupo de Entrevernes, y que dará luces sobre la situación lingüística que entabla el narrador con el mundo narrado.

a. Por el saber: tenemos que Bandeira es dueño del saber-hacer, modalidad actualizante $y$ no virtualizante como el querer-hacer de Otálora. En este sentido, Bandeira posee un programa que se mueve en una línea de acción segura y encubierta, con una mayor trascendencia que Otálora, pues la narración lo ubica en una posición de endiosamiento. Bandeira puede ser descrito, desde esta visión, como la presencia de un Dios arcano y chato (Alazraki, 1976). Posee el saber y es capaz de prever lo que sucederá en el PN de Otálora.

b. Por el querer: es dificultoso plantear esta modalidad en el caso de Bandeira. Existe manifestación modal del querer, pero se encuentra por debajo del umbral del ansia, que pone en evidencia excesiva la performance de Otálora.

Es un querer-hacer controlado. Quiere hacer las cosas, pero aguarda el tiempo suficiente para que el cambio sea radical y no pasajero. Deja hacer y deja ser, permanece observando. Se divierte, manifiesta una especie de sadismo en permitirle al otro que sueñe con el poder. Incluso le permite tenerlo, rozarlo.

c. Por el poder: encontramos que $\mathrm{S} 2$ se encuentra en posición de realizar los cambios que quiera en el entorno, todos los actantes se encuentran en conjunción con él, incluso el mismo Otálora. La manifestación de su poder nace en todo, caso de sí mismo, es reflexiva. Si bien podemos encontrar ciertas manifestaciones adyuvantes, como sus peones, lo realmente gravitante es su imagen, que cubre como un manto todo el universo narrado, es verdadera expresión de poder.

Incluso el mismo Otálora se da cuenta de que ser hombre de Bandeira es tener un lugar especial en el mundo. Las especulaciones sobre su nacimiento ponen de manifiesto el carácter mítico de este actante:

Alguien opina que Bandeira nació del otro lado del Cuareim, en Rio Grande do Sul; eso, que debería rebajarlo, oscuramente lo enriquece de selvas populosas, de ciénagas, de inextricable y casi infinitas distancias" (Borges, El Muerto, 1984).

\section{Programas narrativos y antiprogramas}

a. Haciendo abstracción del narrador, se produce en primer lugar, en la historia de Otálora, una transformación que comporta la situación de disyunción que produce este actante al quitar la vida de un actante-objeto, que sirve para demostrar fortuidad.

b. Se produce un PN sucesivo con la búsqueda de Bandeira por parte de Otálora. Su búsqueda es frustrada, pues cuando lo busca no lo encuentra y sólo la fortuna produce la junción de los dos PN.

c. Si ahora incorporamos el PN del narrador, que es quien inicia el relato, pensamos que se produce una situación en que la conjunción se realiza por el encuentro planeado de dos partes del relato:

\section{PN Otálora v. PN Bandeira}

que el narrador busca exponer, y que son las caras de una misma moneda. Desde el momento de la conjunción de ambos PN se propone un metaPN, en que Otálora debe perder para que el relato obtenga coherencia isotópica.

d. El relato planteado por el narrador pone en movimiento programas y antiprogramas. Postulamos que más allá de lo que podría pensarse, el actante que posee un antiprograma es Otálora: 
Otálora comprende, antes de morir, que desde el principio lo han traicionado, que ha sido condenado a muerte, que le han permitido el amor, el mando y el triunfo, porque ya lo daban por muerto, porque para Bandeira ya estaba muerto (Borges, El Muerto, 1984).

Se trata de la intromisión de Otálora en el programa de Bandeira. Por el hecho de tener un destino claro, hacia la muerte, Otálora opera como un antisujeto a lo largo del texto. Este es oponente a todos los PN del relato, porque es el objeto del texto, y en tanto que objeto, está condenado a fracasar.

Por otro lado, cuando Otálora tiene la posibilidad de realizar un verdadero cambio que lo coloque en posición de poder-realizador, actualizante, no es capaz de hacerlo; esto lo explicaremos luego, proponiendo para ello la priorización de categorías veredictivas en el análisis discursivo.

\section{Manipulación en los personajes}

Se produce un fenómeno que ayudará a comprender mejor el hacer que tiene Bandeira a lo largo de la historia como sujeto manipulador ${ }^{7}$. Precisemos que la manipulación debe tener, como es lógico, dos actantes: uno, el sujeto que ejerce el acto manipulador y otro el destinatario de la manipulación. Este plano es el de un hacer-hacer que puede realizarse de distintas maneras: seducción, intimidación, tentación, provocación.

En el relato, Otálora es tentado, no explícitamente, sino que se lleva a cabo un contrato en el que Otálora permite que se le tiente de manera inconsciente. Es como si Bandeira le dijera: "te apuesto que no eres capaz de realizar esto".

Reséndiz parafrasea a Mauss y dice que para que el intercambio pueda efectuarse, es necesario que las dos partes estén bien seguras del valor, del objeto-valor a recibir en contraparte (Reséndiz: en línea [1999], p. 2). Si esto fuera así estamos en graves aprietos, pues Otálorano conoce la contraparte que espera sus

7 La manipulación es entendida como la "acción que ejerce el hombre sobre otros hombres, tendiente a hacerlos ejecutar un programa dado" ( Reséndiz. 2004. De la manipulación, p. 1). actuaciones y aún así se encuentra en el juego. Esto se debe a que Otálora es un actante truncado que se mueve en un estado de irresolución e incapacidad contante, se encuentra castrado en sus posibilidades de hacer y de ser. De este modo, no puede pensarse que el contrato es siempre resultado del conocimiento, sino también del desconocimiento. Otálora no puede firmar ningún contrato pues es un ser irresoluto, que no logra mantener los pies firmes sobre la tierra para frenar su situación de incertidumbre.

Ahora veamos el actuar de Bandeira en relación a su posición de sujeto manipulador. Visto en el cuadro semiótico, que sistematiza posibilidades, obtenemos:

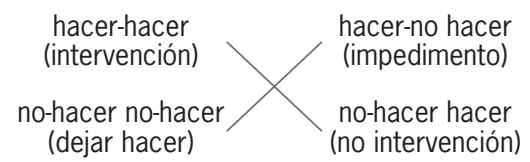

Mirado así, el actuar de Bandeira queda más establecido como un dejar hacer (no-hacer no-hacer), en el que permite, tal vez por divertimiento, el hacer truncado de Otálora. Como manipulador, Bandeira es siempre dueño de la libertad de Otálora. Lo conoce y anticipa, por eso lo manipula.

\section{Análisis discursivo pertinente}

El narrador nos propone entender esta historia pensando en un sujeto particular, a quien él llama "compadrito" y al que le fija, desde la denominación misma de compadrito, hasta los adjetivos que usa para darlo a conocer, un itinerario figurativo preestablecido. Si el Grupo de Entrevernes (1989) ve que un bandido tiene entre sus posibilidades la de atacar a una persona para robarle, entonces el compadrito es un hombre envalentonado, infatuado, que entre otros recorridos posibles, está condenado a perder.

Observemos los adjetivos que desde el principio nos presenta el narrador para referirse a Otálora:

- Compadrito, triste, perecedero.

En este sentido, pensamos que el narrador plantea una historia donde siempre Otálora corre hacia la muerte. Lo más cruel es que aún corre sin darse cuenta, hasta el final, que siempre estuvo derrotado. 
Ahora bien, el recorrido figurativo que sigue Otálora es siempre el que pudo seguir el universo de los compadritos, y con ello, el relato se mantiene en lo que le sucedió a un triste, fatuo e insignificante compadrito. Nada escapa de los márgenes de este destino, los recorridos de los otros personajes se encuentran en función de la derrota del actante-objeto.

Si pensamos con detención, veremos que incluso la muerte del primer sujeto, contribuye a hacer creer a Otálora que es un hombre valiente. Los recorridos figurativos de los personajes -tengamos en cuenta que es una historia de contrabandistas-, se mantienen en las posibilidades figurativas de los bandidos. Ninguno se presenta desarticulando el panorama general del relato. Las isotopías del discurso mantienen una línea que permite ir constatando la inminente derrota de S1.

\section{Las pasiones: su narrativización en la práctica}

\section{Hacia la duda...}

Todo el análisis anterior ha estado orientado en función de dejar en claro como las dos pasiones que hemos colocado como eje del trabajo: duda y desesperanza, tienen una narrativización en el relato. Precisando el objetivo, necesitamos establecer cómo es que se manifiestan las dos pasiones que hemos elegido en el marco de este trabajo. Para ello el cuadro semiótico de veridicción es de especial interés:

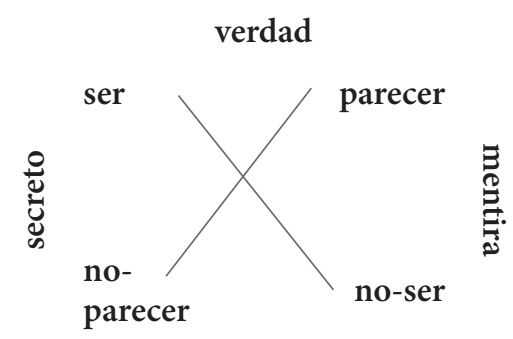

falsedad

Tenemos que de los dos $\mathrm{PN}$ que hemos privilegiado -excluyendo por razones metodológicas los secundarios-, uno se manifiesta como antiprograma y otro como programa. Hemos dicho que en el relato hay una inversión en cuanto al antiprograma, que se manifiesta en Otálora antes que en Bandeira.
Recordando: la duda la hemos definido como un estado que comporta sobre todo un sema de / irresolución/. Obtenemos en el cuadro semiótico los dos extremos del recorrido pasional:

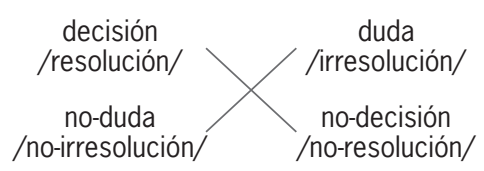

Volviendo al cuadrado veredictivo, tenemos que Otálora se mueve siempre en el lugar del parecer de las modalidades aléticas.

Punto importante en el análisis, es ver el componente de apariencia que se maneja en todo el relato. Es un cuento que logra poner a un sujeto en posición de transformador.

Primero: haciendo pasar a un hombre de la vida a la muerte, pero sin querer-hacer.

Segundo: Otálora a la caza de los bienes de Bandeira, donde pretende una segunda transformación y cambio de estado con el robo, pero que no se lleva a cabo pues el actante no puede hacer $y$, por tanto, tampoco puede-ser. Vemos, según lo anterior, que los dos planos modales, el del ser y hacer, nunca guardan armonía en Otálora.

Su derrota tiene una explicación en el cuadro de veridicción que incorpora la verdad, falsedad, secreto y mentira al cuadro alético. Si Otálora se maneja siempre en lo aparente, es un no-ser que está cruzado por la mentira: Otálora parece valiente, pero queda claro que no lo es cuando el narrador nos señala: "una puñalada feliz le ha revelado que es un hombre valiente" (Borges, El Muerto, 1984).

¿Quién se lo ha revelado? No su gallardía ni su fiereza. Fue la suerte de haber apuñalado a un hombre, sin tener el mérito de hacerlo.

Por su parte, Bandeira es un actante opuesto a Otálora. Es ser propiamente tal, pero esconde lo que es: no- parecer. Por eso Bandeira se atreve a entrometerse en su camino y planear contra él. Bandeira está en el lugar del secreto y eso le da una ventaja, pues lo mantiene oculto hasta que decide actuar.

Se puede incorporar a otro actante que juega, en este plano de mentiras y secretos, un papel decisivo. Se trata de Ulpiano Suárez. Este actante hace su aparición hacia el final del relato, pero tiene un 
papel decisivo. Este, al igual que Bandeira, es ser, no-parecer y actúa en secreto, a primera vista para traicionar a su jefe, Bandeira, pero hacia el final del texto se ve que el secreto es parte de la estratagema de engaño contra Otálora.

- Los PN de Bandeira y Ulpiano Suárez se encuentran en conjunción, protegidos por el secreto, se divierten con la performance de Otálora.

Si desde la introducción el Narrador hace ver a Otálora como un hombre que no es dueño de sí mismo, tiende siempre a la /irresolución/, que hemos examinado en la duda. Su estado de /irresolución/ queda mucho más claro si miramos que en un momento dado, Otálora, que ha logrado tomar dominio de los negocios de Bandeira, tiene la posibilidad de matar a su jefe y de ese modo tomar el control total y de manera radical. Sin embargo, sucede los siguiente: "Bandeira, sin embargo, siempre es nominalmente el jefe. Da órdenes que no se ejecutan; Benjamín Otálora no lo toca, por una mezcla de rutina y de lástima." (Borges, El Muerto, 1984).

La rutina es un lexema que contiene un sema de /duratividad/, igual que el destino. Pensamos que el estado irresoluto, en que incurre Otálora cuando tiene la posibilidad de tomar el control total, se debe precisamente al componente temporal de rutina en que él, desde siempre, no fue capaz de hacerse cargo de sus posibilidades en el hacer y en el ser.

En el hacer, desde el comienzo: "Una puñalada feliz" logra producir una transformación disyuntiva. Que sea "feliz" supone que no tuvo verdadera intención de hacerlo y que ocurrido el hecho fortuito; sintió que era un hombre valiente sin serlo realmente.

La /perplejidad/, que es otro de los semas que contiene la duda como pasión, se manifiesta en la imposibilidad en el hacer. Se ha transitado, en este estado pasional de duda, desde un estado de no tensión o seguridad, hasta la máxima tensión que produce tener dos o más posibilidades y no saber cuál tomar. S1 es un ser perplejo que tiene un actuar errático.
Se trata, como lo dice Fabbri (2000), de una pasión eminentemente volitiva y de conocimiento. En este caso particular, la cognición de Otálora se encuentra chata. En el lugar en que se han encadenado temporalmente los hechos -en su destino-, la duda se inserta con la misma temporalidad de todo ese destino. En el lugar en que el estado debiera tender hacia la homeóstasis con la toma de una decisión certera, el actante es incapaz de hacerlo. La /perplejidad/ que le produce la imagen de Bandeira es una de las posibles causas de esta irresolución.

\section{Hacia la desesperanza...}

El mundo que nos propone el narrador es un mundo evidentemente desesperanzado. Si para mostrar una realidad X se ha elegido de manera no azarosa una historia particular, esto expone una ideologización del universo narrado.

Presenciamos un mundo en que desde el principio se ha condenado a un hombre a su destino trágico. La /incertidumbre/ que produce la duda deviene en Otálora en un estado de desesperanza, no respecto a su fin, pues cuando en el último párrafo se ve con la pistola en el pecho tiene la certeza de que va a morir; es más bien la desesperanza respecto a su actuar pasado, que ha sido burlado. Descubre que no ha tenido la facultad de darse cuenta de lo que pasaba ante sus narices y por eso cabila:

Otálora comprende, antes de morir, que desde el principio lo han traicionado, que ha sido condenado a muerte, que le han permitido el amor, el mando y el triunfo, porque ya lo daban por muerto, porque para Bandeira ya estaba muerto (Borges, El Muerto, 1984).

Todos han conspirado para su fin. En ese mundo no había posibilidad de vencer, pues desde siempre estuvo perdido. Se trata de un estado pasional de extrema decadencia, donde un ser humano no tiene nada que hacer contra su destino. Los encadenamientos de hechos que suceden en este destino sólo contribuyen a hundir a Otálora, y como es un personaje trunco en las posibilidades de decidir, no logra tener la facultad para operar, por ejemplo, con secreto, como sí lo hacen los actantes triunfadores. 
El texto propone conocer un destino, que sirve de ejemplo por el carácter parabólico que establece el narrador, de un hombre que no pudo hacer nada contra su destino y tampoco ante esta figura divinizada que es Bandeira.

El tema borgeano de un mundo desesperanzado, como el que presencia Otálora luego de obtener esa ventana de luz, que en su final le permite saber que se han reído de él, es recurrente en otras obras borgeanas. Otálora pudo morir no sabiendo nada, siendo siempre un ser anodino.

¿Por qué Otálora debe saberlo? ¿Qué lo obliga?

La luz reveladora que entra por la ventana de la conciencia de Otálora, cuando se da cuenta de su poquedad, es una luz cruel, flagelante, pero al fin de cuentas es una luz que viene a decirte: ¡ino eres nada, para mí, no eres nada!! Recordemos que la imagen que Borges tiene de dios, es la de un niño que se divierte con nosotros.

\section{Conclusiones provisorias}

Respondiendo a los objetivos planteados:

1. De manera general, la semiótica ha devenido críticamente en formación de semióticas particulares y la incorporación de nuevos objetos de estudio para su análisis. Dentro de esto, las pasiones han surgido como una superación de los dualismos que se presentan en la cultura occidental de manera clásica y que separan tajantemente pasión/razón. En este sentido, autores tradicionalmente estructuralistas como Greimas, conciben un nuevo estudio de las manifestaciones pasionales en el texto. Estos trabajos son retomados, entre otros, por Paolo Fabbri, quien plantea

\section{Bibliografía}

Alazraki, J. (1974). La prosa narrativa de Jorge Luis Borges. Madrid: Gredos.

Blanco, D. (2006). Semiótica y ciencias humanas. Letras, Vol. 77, 111-112.

Imbert, E. (1999). Borges y su concepción de mundo. Boletín de la Academia Argentina de Lenguas Anejo I. Homenaje a Jorge Luis Borges. Argentina. un marco conceptual, desde dónde y cómo observar las pasiones.

2. De manera general, las pasiones son posibles de estudiar desde la semiótica, bajo el alero de la metodología greimasiana de las competencias modales y el estudio de la narratividad.

3. De manera general, se observa cómo el amplio estudio de la obra borgeana demuestra que es una de las más relevantes, en escritores de habla hispana, a nivel universal. Esto se debe a lo complejo de sus propuestas estéticas, que no hay duda, se imbrican con la filosofía, dando una textura única. Sin embargo, en la búsqueda de nuevos espacios de investigación, no hay estudios que indaguen en las manifestaciones pasionales en su obra.

4. De manera puntual, es posible constatar que duda y desesperanza se manifiestan en el cuento El Muerto como una determinada performance que lleva al personaje/objeto de este relato, Otálora, hacia el encuentro de una muerte desde el principio conocida. La irresolución, la perplejidad, la no-acción de Otálora, devienen finalmente en la configuración de un mundo narrado desesperanzado, cuando el personaje descubre que ha sido engañado desde siempre. Se le ha permitido el poder para poder burlarse de su vida de compadrito.

5. Prolegómeno, es necesario avanzar hacia la consolidación metodológica de estas investigaciones y también hacia la indagación de las pasiones en una obra tan importante como la de Jorge Luis Borges.Ø

Borges, J. (1968). Ficciones. Buenos Aires: Emecé. (1984). El Aleph. Santiago: Ercilla.

Bloom, H. (1986). Jorge Luis Borges. New York. New Haven. Philadelphia. Chelsea: House Publishers.

Carrizo, A. (1982). Borges el memorioso. México: Fondo de Cultura Económica. 
Fabbri, P. (1995). Las tácticas de los signos. Barcelona: Gedisa. (2000). El giro semiótico. Barcelona: Gedisa.

Ferrari, O. (1985). Borges en Diálogo. Buenos Aires: Grijalbo.

Ferrater Mora, J. (1980). Diccionario de filosofía abreviado. Argentina: Sudamericana.

Greimas, A. (1989). Del sentido II. Ensayos de Semiótica. Madrid: Gredos.

(1983). La semiótica del texto. Ejercicios prácticos. Análisis de un cuento de Maupassant. Barcelona: Paidós.

Greimas, A. y Fontanille, J. (1994). Semiótica de las pasiones. De los estados de cosas a los estados de ánimo. México: Siglo XXI Editores.

Greimas, A. y Courtés, J. (1982). Semiótica. Diccionario razonado de la teoría del lenguaje I. Madrid: Gredos.

Grijalbo. (1995). Diccionario Enciclopédico. Barcelona: Grijalbo.

Grupo de Entrevernes. (1989). Signos y parábolas. Semiótica y texto evangélico. Madrid: Ediciones Cristiandad.

Kazmierczak, M. (2001). La metafísica idealista en los relatos de Jorge Luis Borges. Barcelona: Tesis doctoral.

Larousse. (1992). Diccionario, Gran Enciclopedia. Tomo 7 y 8 . Barcelona: Planeta.

Lozano, J., Peña-Marín, C. y Abril, G. (1999). Análisis del discurso. Hacia una semiótica de la interacción textual. Madrid: Cátedra.

Marina, J. (2007). En laberinto sentimental. Barcelona: Compactos de Anagrama.

McMurray, G. (1980). Jorge Luis Borges. New York: Ungar.

Naveira, L. (2003). Palabra y pensamiento en Borges. Argentina: Tesis doctoral. Disponible en: www.tdx. cesca.es/tesis_ub/available/ tdx-0613105-105200/ tesis_lnaveira.pdf

Nitrihual, L. (2007). Borges y Bolaño: un juego intertextual desde la divergencia. Espéculo, Revista de estudios literarios ( $\mathrm{N}^{\circ}$ 36). Universidad Complutense de $\mathrm{Ma}$ drid. ISSN: 1139-3637. Disponible en: http://www. ucm.es/info/especulo/numero36/borgbola.html.

(2008a). Bolaño: ¿Civilización y Barbarie? El gaucho insufrible. Reescritura del tópico civilizaciónbarbarie. Espéculo, Revista de estudios literarios ( $\mathrm{N}^{\circ}$ 38). Universidad Complutense de Madrid. ISSN: 1139-3637. Disponible en: http://www.ucm.es/info/ especulo/numero38/civibarb.html.

(2008b). Acercamiento semiótico a la fe como pasión. Revista Adversus, V 10-11. Diciembre-Abril 2008.

Nuño, J. (1986). La Filosofía en Borges. México: Fondo de Cultura Económica.

Pierce, C. (1902). Trad. S. Barrena 2004. La lógica considerada como semiótica. www.unav.es/gep/L75.pdf

Reséndiz, R. (2000). De la manipulación. Disponible en: http://hiperlab.politicas.unam.mx

(2000). La semiótica de A. J. Greimas. Disponible en: http://hiperlab.politicas.unam.mx

Rodríguez, E. (1978). Diálogos I. Argentina: Sudamericana.

Ruiz, X. (s.f. 1997). Entrevista a Paolo Fabbri. Observatorio. Quaderns del CAC, Vol 15. www.audiovisualcat. net/publicaciones/Q15castfabbri.pdf

Salvador, G. (2004). Borges lector de Qohélet. Barcelona: Tesis doctoral. www.hum.au.dk/romansk/borges/ bsol/salvador.pdf

Sarlo, B. (1995). Borges un escritor de las orillas. Buenos Aires: Ariel.

Teitelboim, V. (1995). Los dos Borges. Argentina: Sudamericana.

Toro, A. (1999). "Borges/Derrida/Foucault: Pharmakeus/ Heterotopia o más allá de la literatura ('hors-littérature'): escritura, fantasma, simulacros, máscaras, carnaval y... Atlön/Tlön, Ykva/Uqbar, Hlaer, Jangr, Hrön(n)/Hrönir, Ur y otras cifras”. En: Alfonso de Toro/Fernando de Toro (eds.). Jorge Luis Borges. Pensamiento y saber en el siglo XX. Frankfurt a. M. I Madrid: Vervuert/Iberoamericana, 139-163. 